ABDIMAS: Jurnal Pengabdian Masyarakat Universitas Merdeka Malang
Vol.7(1) February 2022, 124-130
U-ISSN: 2721-138X e-ISSN: 2548-7159
Uttp://jurnal.unmer.ac.id/index.php/jpkm

\title{
Mobile-health for recording and monitoring nutritional status of toddler during COVID-19 pandemic era
}

\author{
Aplikasi mobile-health untuk pencatatan dan monitoring status gizi balita \\ pada masa pandemi COVID-19
}

\author{
Atika Hendryani', Vita Nurdinawati', Ernia Susana1, Ma'murotun'1, Didit Damayanti Ramadhan² \\ 'DepartemenTeknik Elektromedik, 2Departemen Gizi, Poltekkes Kemenkes Jakarta II \\ Jl. Hang Jebat III/F3 Kebayoran Baru, Jakarta Selatan, DKI Jakarta, 12120, Indonesia
}

\begin{abstract}
ARTICLE INFO:
Received: 2021-05-11

Revised: 2021-08-14

Accepted: 2021-11-27

Keywords:

Nutrition app COVID-19, Mobilehealth, Integrated Healthcare Center, Health technology

ABSTRACT

Indonesia has a large population in the world, and this is both an advantage and a challenge. The importance of recording and monitoring nutrition from the age of toddlers is a form of intervention to create a productive population. Integrated Healthcare Center or posyandu is a community empowerment to monitor nutrition independently and sustainably. The pandemic caused by COVID-19 also affects the implementation of posyandu in Indonesia, one of which is in densely populated areas, namely Kelurahan Duri Selatan Jakarta Barat. This community service activity aims to apply mobile-health technology so that the nutrition monitoring activities of toddlers in posyandu continue to run during this pandemic. The technology used in this community service activity is a mobile-health application based on android, which is a form of application of technology from research. The method used is the provision of material online, then conducting assistance implementation practice. Evaluation of the results was achieved by applying pre-test and post-test to posyandu cadres and citizens. The evaluation results showed increased knowledge of posyandu cadres and residents after community service activities. This community service activity provides an alternative application of new technologies for community empowerment in improving nutritional status.
\end{abstract}

(C) 2022 Abdimas: Jurnal Pengabdian Masyarakat Universitas Merdeka Malang This is an open access article distributed under the CC BY-SA 4.0 license (https://creativecommons.org/licenses/by-sa/4.0/)

How to cite: Hendryani, A., Nurdinawati, V., Susana, E., Ma'murotun, M., \& Ramadhan, D. D. (2022). Mobile-health for recording and monitoring nutritional status of toddler in posyandu during COVID-19 pandemic era. Abdimas: Jurnal Pengabdian Masyarakat Universitas Merdeka Malang, 7(1), 124-130. https://doi.org/10.26905/abdimas.v7i1.5786

\section{PENDAHULUAN}

Indonesia tercatat memiliki populasi penduduk sebanyak 265 juta jiwa menduduki peringkat ke empat sebagai negara dengan jumlah penduduk terbanyak. Menurut data BPS pada tahun 2035 Indonesia diproyeksikan akan mencapai puncak pertumbuhan penduduk produktif (bonus demografi), diperkirakan jumlah penduduk Indonesia pada 2045 mencapai 321 juta jiwa dimana penduduk usia produktif mencapai 209 juta jiwa (Badan Pusat Statistik, 2018). 
Angka penduduk produktif tersebut tidak akan tercapai jika tidak dilakukan intervensi, bahkan bonus demografi yang diharapkan bisa berbalik menjadi beban negara. Salah satu faktor yang dapat menghambat jumlah angka penduduk produktif tersebut adalah masalah gizi, tidak hanya gizi kurang tetapi juga gizi lebih atau obesitas yang banyak ditemui di kota besar seperti di Jakarta. Agar masalah gizi ini dapat diatasi dan dicegah maka perlu dilakukan kegiatan pencatatan dan monitoring gizi status gizi sejak dini yaitu pada balita agar manfaat bonus demografi dapat tercapai.

Salah satu kegiatan yang dilakukan masyarakat dalam melakukan pencatatan dan monitoring gizi adalah kegiatan Pos Pelayanan Terpadu (Posyandu). Posyandu adalah bentuk upaya kesehatan dengan memberdayakan masyarakat (Tse et al., 2017). Kegiatan posyandu dilakukan di tingkat kelurahan dengan bantuan tenaga kesehatan di puskesmas dan kader kesehatan yang berasal dari masyarakat itu sendiri. Posyandu memberikan pengaruh yang cukup besar dalam peningkatan kesehatan di masyarakat dan kader posyandu yang cakap juga menjadi faktor penting keterlibatan masyarakat untuk aktif (Dewi \& Anisa, 2018; Tse et al., 2017). Penelitian juga menunjukkan adanya pengaruh positif terhadap frekuensi penimbangan di posyandu dengan status gizi balita (Amir et al., 2017).

Pada masa pandemi akibat COVID-19 yang di Indonesia mulai terjadi sejak tahun 2020, pemerintah menetapkan kebijakan pembatasan kegiatan mengumpulkan orang banyak yang mengakibatkan kerumunan, karena itu beberapa kegiatan posyandu menjadi terhenti. Hal ini menyebabkan monitoring status gizi balita tidak terlaksana dan jika masalah ini dibiarkan terus menerus maka akan menimbulkan masalah gizi yang tidak dapat diantisipasi sebelumnya. Berdasarkan masalah tersebut perlu diterapkan suatu teknologi dan metode agar kegiatan pencatatan dan monitoring gizi balita tetap dapat berjalan di era pandemi COVID-19 ini. Beberapa metode yang diterapkan adalah melalui penggunaan poster (Caesaron et al., 2021) atau menggunakan aplikasi handphone Android (Sari et al., 2021).

Teknologi yang tepat digunakan adalah teknologi mobile-health menggunakan handphone, hal ini karena media yang paling banyak diakses oleh ibu-ibu adalah perangkat seluler atau handphone, karena itu upaya peningkatan pengetahuan melalui aplikasi handphone berbasis Android cukup efektif untuk memberikan pengetahuan dan juga mencegah terjadinya masalah gizi pada balita (PEW Research Center, 2018; Bader et al., 2007). Secara global terjadi peningkatan penggunaan aplikasi di handphone, hal ini dapat meningkatkan potensi untuk mempromosikan perilaku nutrisi yang sehat dan menjadi media promosi kesehatan yang paling cepat berkembang (Gabrielli et al., 2017; Pires et al., 2015). Selain itu, beberapa penelitian menunjukkan adanya pengaruh yang kuat antara pengetahuan ibu terhadap peningkatan gizi anak (Aridiyah et al., 2015; Ni'mah \& Nadhiroh, 2015; Ulfani et al., 2011).

Kegiatan pengabdian kepada masyarakat ini bertujuan untuk memberikan sosialisasi tentang aplikasi mobile-health untuk pencatatan dan monitoring status gizi balita di posyandu (Hendryani \& Susana, 2020). Kegiatan ini merupakan bentuk hilirisasi teknologi hasil penelitian kepada masyarakat dan membantu memberdayakan masyarakat dalam melakukan monitoring status gizi balita secara mandiri. Aplikasi mobile-health yang akan diterapkan merupakan aplikasi berbasis Android yang dapat digunakan oleh petugas di posyandu dan juga ibu balita.

\section{METODE}

Kondisi pandemi COVID-19 tentunya memerlukan pendekatan yang berbeda dalam mengupayakan kelangsungan pelayanan kesehatan balita. Pemanfaatan aplikasi berbasis Android melalui telepon genggam yang merupakan hilirisasi teknologi hasil penelitian akan memudahkan para kader dalam melakukan pencatatan dan monitoring tumbuh kembang dan status gizi balita di wilayahnya. Tentunya hal ini dapat menjadi alternatif solusi di masa pandemi COVID-19 ketika kondisi mengharuskan masyarakat untuk disiplin dalam mengurangi mobilitas, menghindari kerumunan, dan menjaga jarak fisik dengan orang lain. 
ABDIMAS: Jurnal Pengabdian Masyarakat Universitas Merdeka Malang

Volume 7, No 1, February 2022: 124-130

Kegiatan Pengabdian kepada Masyarakat (PKM) dikemas dalam bentuk pelatihan atau workshop menggunakan media daring dan pendampingan praktik secara terbatas dengan sasaran kader kesehatan posyandu di lingkungan Kelurahan Duri Selatan, Jakarta Barat. Bentuk ini dipilih karena di era pandemi tidak memungkinkan bagi warga untuk berkumpul dan membuat kerumunan. Kegiatan ini merupakan kolaborasi antara dosen di lingkungan Poltekkes Kemenkes Jakarta II khususnya dari Jurusan Teknik Elektromedik dan Jurusan Gizi serta posyandu di Kelurahan Duri Selatan, Jakarta Barat.

Kegiatan diawali dengan melakukan survei pendahuluan ke posyandu di Kelurahan Duri Selatan, Jakarta Barat. Dari hasil survei pendahuluan dilakukan analisis situasi lingkungan sehingga lokasi posyandu ini dipilih karena padatnya jumlah penduduk di wilayah kelurahan tersebut, dan juga kegiatan posyandu cukup aktif (BPS Jakarta Barat, n.d.). Survei dilakukan dengan melakukan pengamatan langsung di tempat lokasi posyandu dan melakukan wawancara terhadap petugas dan kader posyandu beserta petugas di Kelurahan Duri Selatan. Setelah mendapatkan data hasil observasi dan wawancara selanjutnya dilakukan diskusi dengan kader posyandu dan perangkat Kelurahan Duri Selatan untuk menentukan metode pelaksanaan yang tepat sasaran.

Secara keseluruhan, kegiatan PKM dibagi menjadi dua tahap, yaitu: (1) Inisiasi dan pengenalan aplikasi mobile-health bagi 25 peserta pelatihan yang terdiri dari petugas, kader posyandu, dan warga; (2) Pendampingan praktik terbatas untuk pelaksanaan monitoring status gizi balita menggunakan aplikasi mobile-health bagi lima kader yang ditunjuk.

Tahap pertama adalah inisiasi dan pengenalan aplikasi mobile-health. Kegiatan ini dilaksanakan secara online pada tanggal 21 Oktober 2020 jam 09.00 sampai dengan jam 13.00 menggunakan media Zoom Meeting yang materinya disampaikan dengan pendekatan ceramah, pemutaran video praktik kegiatan, dan dilanjutkan dengan diskusi. Pada kegiatan daring ini peserta mengikuti ceramah dari rumah masing-masing. Gabungan dari ketiga metode tersebut diharapkan dapat memberikan gambaran yang utuh tentang praktik pencatatan, penggunaan, dan pemanfaatan data digital dalam monitoring status gizi balita serta cara pemeliharaan dan kalibrasi peralatan timbangan digital yang digunakan dalam ketugasannya. Video praktik merupakan nilai lebih dari kegiatan ini. Keberadaannya akan memudahkan peserta dalam membangun pola pikir dari apa yang sedang didengar dan dilihatnya. Hal ini diharapkan dapat meningkatkan kemampuan para kader dalam memberikan pelayanan kesehatan kepada masyarakat di wilayahnya.

Tahap kedua selanjutnya dilakukan pada tanggal 21 Nopember 2020 secara luring di Aula Kelurahan Duri Selatan, Jakarta Barat. Tahap ini dilakukan pendampingan praktik terbatas kepada petugas dan kader posyandu sebanyak 10 orang yang ditunjuk yang selanjutnya akan mengajarkan kepada warga. Pada kegiatan ini masyarakat diharapkan dapat melakukan kegiatan secara mandiri setelah dilakukan pendampingan.

Ketercapaian tujuan kegiatan pengabdian kepada masyarakat dilakukan dengan mengevaluasi pemberian tes sebelum dan sesudah dilaksanakan kegiatan. Sebelum dimulainya kegiatan, diberikan sepuluh pertanyaan kualitatif (pre-test) kepada petugas, kader posyandu, dan warga. Setelah dilakukan kegiatan diberikan pertanyaan kualitatif (post-test) kembali kepada petugas, kader posyandu, dan warga. Hasil pre-test dan post-test kemudian dibandingkan secara kualitatif untuk mengetahui peningkatan pengetahuan petugas, kader posyandu, dan warga.

\section{HASIL DAN PEMBAHASAN}

Kegiatan ini telah dilaksanakan secara daring menggunakan media Zoom Meeting pada tanggal 19 November 2020. Peserta yang hadir terdiri dari petugas kesehatan, kader posyandu Kelurahan Duri 
Selatan, dan warga. Materi yang disampaikan pada kegiatan ini adalah instalasi aplikasi mobile-health beserta cara penggunaannya, pemanfaatan data digital sebagai media untuk monitoring status gizi balita, tata cara penggunaan alat timbang dan alat ukur digital, serta cara kalibrasi dan pemeliharaan sederhana pada alat timbang dan ukur di posyandu. Materi tersebut cukup lengkap agar kegiatan posyandu dapat dilakukan secara mandiri oleh kader dan warga.

Pertemuan yang dilakukan secara daring ini cukup menarik minat warga, karena dapat dilakukan dari rumah masing-masing. Materi pertama diajarkan cara melakukan instalasi dan menggunakan aplikasi mobile-health seperti terlihat pada Gambar 1.

Setelah diajarkan cara instalasi dan penggunaan aplikasi selanjutnya disampaikan materi berikutnya secara bergantian. Penyampaian materi tidak hanya dalam bentuk ceramah namun juga dalam bentuk pemutaran video. Hal ini agar materi dapat lebih mudah dipahami dan tidak menimbulkan rasa bosan terhadap kegiatan ini. Kegiatan sosialisasi secara daring dapat dilihat pada dokumentasi kegiatan pada gambar 2.
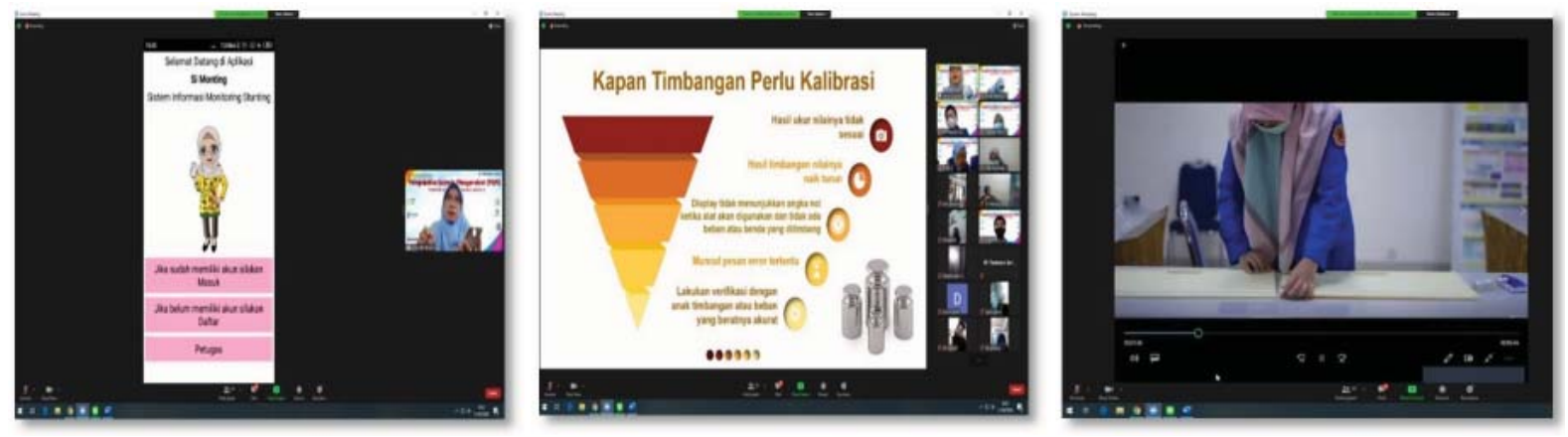

Gambar 1. Instalasi dan pengenalan aplikasi mobile-health menggunakan handphone Android Gambar 2. Penyampaian materi penggunaan dan kalibrasi timbangan dan pemutaran video cara menggunakan timbangan digital

Pada tahap ini peserta antusias mendengarkan materi dan video yang disampaikan. Banyak pengetahuan baru yang didapatkan peserta, hal ini dapat dilihat dari meningkatnya pengetahuan peserta tentang cara mengkalibrasi timbangan, menggunakan handphone untuk mencatat status gizi, dan menggunakan data digital hasil pencatatan di posyandu untuk monitoring status gizi balita. Secara kualitatif terjadi peningkatan pengetahuan yang cukup signifikan dengan melakukan wawancara kepada peserta yang sudah diberikan materi.

Wawancara dilakukan dengan memberikan pertanyaan kepada beberapa peserta tentang bagaimana cara mengkalibrasi timbangan, sebelum dilakukan ceramah tidak ada peserta yang dapat menjawab. Setelah dilakukan ceramah peserta dapat menjawab dan menjelaskan cara kalibrasi timbangan dengan baik.

Monitoring menggunakan aplikasi Android hanya sebagai informasi awal mengenai kondisi balita, selanjutnya kader posyandu tetap perlu melakukan tindakan untuk mengatasi indikasi kekurangan gizi kepada balita yang dimaksud. Hal ini menjadi solusi di masa pandemi COVID-19 dimana tidak memungkinkan kader posyandu dan ibu balita mengikuti kegiatan posyandu.

Selama masa pembatasan kegiatan di era pandemi COVID-19, kegiatan posyandu hampir tidak pernah dilakukan lagi. Berdasarkan masalah tersebut kemudian kegiatan pendampingan praktik dilakukan kepada lima orang kader posyandu yang selanjutnya akan mengajarkan kepada petugas dan 
ABDIMAS: Jurnal Pengabdian Masyarakat Universitas Merdeka Malang

Volume 7, No 1, February 2022: 124-130

warga yang lain. Kegiatan praktik dilakukan di aula Kelurahan Duri Selatan Jakarta Barat. Tahapan praktik yang dilakukan dengan beberapa tahap.

\section{Praktik penggunaan timbangan digital}

Timbangan digital yang digunakan adalah timbangan yang sudah dilengkapi menu otomatis agar ibu dapat mandiri menimbang berat badan anaknya. Dengan timbangan digital ini warga dapat menimbang sendiri berat balitanya, sehingga tidak perlu berkumpul menunggu giliran ditimbang oleh petugas. Gambar 3 menunjukkan kegiatan praktik penggunaan timbangan. Setelah melakukan praktik pada ketiga kegiatan tersebut, petugas yang dilatih diharapkan dapat mengajarkan kepada warga dan petugas yang lain bagaimana menggunakan aplikasi mobile-health dan juga bagaimana menjalankan kegiatan posyandu di era pandemi COVID-19.

\section{Mencatat data ke dalam aplikasi mobile-health}

Aplikasi ini dapat digunakan ibu secara mandiri untuk mengisikan data hasil penimbangan sebelumnya. Kegiatan ini dapat dilakukan warga kapan saja dan dimana saja menggunakan handphone. Setelah diisikan datanya ke aplikasi selanjutnya dapat diakses oleh petugas dan kader posyandu untuk me-monitoring status gizi balita tersebut.

\section{Kalibrasi dan pemeliharaan alat timbangan}

Kegiatan ini perlu dilakukan agar timbangan selalu dalam kondisi baik dan siap pakai. Pada tahap ini petugas posyandu diajarkan bagaimana cara melakukan kalubrasi pada timbangan dan pemeliharaan sederhana agar alat dapat berfungsi dengan baik dalam jangka waktu yang lama. Secara keseluruhan kegiatan pelaksanaan posyandu di era pandemi COVID-19 dapat dilihat pada Gambar 4.

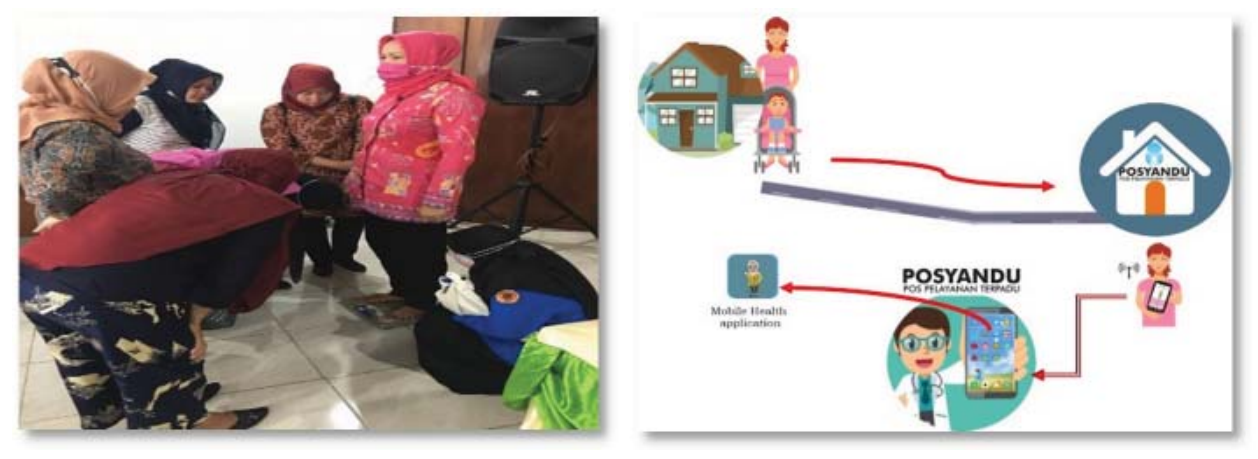

Gambar 3. Pendampingan praktik menggunakan timbangan digital untuk kader posyandu di Kelurahan Duri Selatan

Gambar 4. Alur pelaksanaan pencatatan dan monitoring gizi menggunakan aplikasi mobile-health di posyandu

Penjelasan atau keterangan mengenai Gambar 4 adalah sebagai berikut: (1) Ibu membawa balita ke posyandu untuk melakukan penimbangan dan pengukuran tinggi badan. Protokol kesehatan tetap dilakukan dengan menggunakan masker dan memakai hand sanitizer sebelum dan sesudah menimbang. Pada kegiatan ini ibu dapat melakukan secara mandiri atau dibantu oleh kader posyandu; (2) Ibu mengisi data hasil pencatatan pada aplikasi menggunakan handphone, pencatatan dapat dilakukan secara mandiri di rumah; (3) Hasil pencatatan dapat dibaca dan di-monitoring oleh ibu dan petugas posyandu. 
Kegiatan pengabdian kepada masyarakat ini adalah bentuk penyebaran teknologi hasil penelitian yang telah dilakukan yaitu aplikasi mobile-health untuk monitoring gizi di posyandu. Selain itu kegiatan ini juga memberikan pengetahuan dan solusi bagi masyarakat bagaimana pelaksanaan posyandu dapat tetap berjalan di era pandemi COVID-19.

Kegiatan ini tidak berhenti hanya pada masa pandemic COVID-19 namun diharapkan tetap berkelanjutan dilakukan di posyandu agar warga dapat secara mandiri menggunakan teknologi untuk monitoring status gizi balita. Untuk mencapai tujuan tersebut perlu dukungan pemerintah setempat agar kegiatan ini didukung sarana dan prasarana yang memadai seperti perangkat handphone dan paket internet bagi petugas. Data dan informasi yang dikumpulkan pada aplikasi mobile-health akan sangat berguna bagi pemerintah dalam mengetahui status gizi anak balita di lingkungannya, sehingga masalah gizi dapat diatasi sejak dini.

\section{SIMPULAN DAN SARAN}

Pelaksanaan kegiatan pengabdian kepada masyarakat yang dilakukan dalam bentuk penerapan aplikasi mobile-health untuk monitoring gizi di Posyandu Kelurahan Duri Selatan, Jakarta Barat berjalan dengan baik. Tujuan kegiatan ini untuk memberikan solusi pelaksanaan posyandu di era pandemi COVID-19 dapat tercapai. Kegiatan posyandu dapat dilakukan tanpa harus berkumpul dan menyebabkan kerumunan, selain itu data hasil pencatatan dapat tersimpan dan digunakan untuk monitoring oleh petugas posyandu dan warga. Kegiatan yang diikuti oleh petugas, kader posyandu, dan warga memberikan solusi dan pengetahuan baru dalam pelaksanaan pencatatan dan monitoring gizi balita.

Perlu dilakukan evaluasi secara kontinyu pada mitra posyandu agar teknologi yang telah diajarkan dapat dimanfaatkan dan dilanjutkan secara berkala. Pihak mitra dapat juga memberikan masukan kepada stakeholder untuk dukungan pemanfaatan teknologi yang telah diajarkan.

\section{UCAPAN TERIMA KASIH}

Terima kasih kepada Lurah dan Kader Posyandu Duri Selatan, Kecamatan Tambora, Jakarta Barat sebagai mitra pada kegiatan pengabdian kepada masyarakat ini.

\section{DAFTAR PUSTAKA}

Amir, A., Rochimiwati, S. N., Asbar, R., \& Toro, R. A. (2017). Frekuensi penimbangan dengan status gizi balita. Media Gizi Pangan, 24(1), 64-68. https://doi.org/10.32382/mgp.v24i1.292

Aridiyah, F. O., Rohmawati, N., \& Ririanty, M. (2015). Faktor-faktor yang mempengaruhi kejadian stunting pada anak balita di wilayah pedesaan dan perkotaan. E-Jurnal Pustaka Kesehatan, 3(1), 163-170. https://doi.org/10.1038/nature02345

Bader, P., Travis, H. E., \& Skinner, H. A. (2007). Smartphone technology and apps: Rapidly changing health promotion. American Journal of Public Health, 97(8), 1434-1443.

Badan Pusat Statistik. (2018). Proyeksi penduduk Indonesia 2015-2045. Jakarta: Badan Pusat Statistik.

BPS Jakarta Barat. (n.d.). BPS kota administrasi Jakarta Barat. Jakarta: Badan Pusat Statistik Jakarta Barat. 
ABDIMAS: Jurnal Pengabdian Masyarakat Universitas Merdeka Malang

Volume 7, No 1, February 2022: 124-130

Caesaron, D., Salma, S. A., Prasetio, M. D., \& Rifai, M. H. (2021). Edukasi dan sosialisasi pencegahan dan pengendalian COVID-19 melalui media poster di Desa Bojongsoang, Kabupaten Bandung. Abdimas: Jurnal Pengabdian Masyarakat Universitas Merdeka Malang, 6(2), 221-229. https://doi.org/10.26905/abdimas.v6i2.5354

Dewi, R., \& Anisa, R. (2018). The influence of Posyandu Cadres credibility on community participation in health program. Jurnal The Messenger, 10(1), 83-92.

https://doi.org/10.26623/themessenger.v10i1.596

Gabrielli, S., Dianti, M., Maimone, R., Betta, M., Filippi, L., Ghezzi, M., \& Forti, S. (2017). Design of a mobile app for Nutrition Education (TreC-LifeStyle) and formative evaluation with families of overweight children. JMIR MHealth and UHealth, 5(4), e7080.

https://doi.org/10.2196/mhealth.7080

Hendryani, A., \& Susana, E. (2020). Pengembangan aplikasi mobile health berbasis Android untuk monitoring dan evaluasi stunting. Jurnal Sehat Mandiri, 15(1), 24-32. https://doi.org/10.33761/jsm.v15i1.188

Ni'mah, K., \& Nadhiroh, S. R. (2015). Faktor yang berhubungan dengan kejadian stunting pada balita. Media Gizi Indonesia, 10(1), 13-19. http://dx.doi.org/10.20473/mgi.v10i1.13-19

PEW Research Center. (2018). Mobile fact sheet. PEW Research Center.

Pires, I. M., Garcia, N., \& Flórez-Revuelta, F. (2015). Multi-sensor data fusion techniques for the identification of activities of daily living using mobile devices. In Doctoral Consortium of ECML PKDD 2015.

Sari, R., Yanti, M. K. D., Liliana, D. Y., \& Ismail, I. E. (2021). Pembuatan aplikasi monitoring karantina mandiri Orang dalam Pengawasan (ODP) COVID-19 di Kota Depok. Abdimas: Jurnal Pengabdian Masyarakat Universitas Merdeka Malang, 6(2), 143-152. https://doi.org/10.26905/abdimas.v6i2.5090

Tse, A. D. P., Suprojo, A., \& Adiwidjaja, I. (2017). Peran kader posyandu terhadap pembangunan kesehatan masyarakat. Jurnal Ilmu Sosial dan Ilmu Politik Universitas Tribhuwana Tunggadewi, $6(1), 60-62$.

Ulfani, D. H., Martianto, D., \& Baliwati, Y. F. (2011). Faktor-faktor sosial ekonomi dan kesehatan masyarakat kaitannya dengan masalah gizi underweight, stunted, dan wasted di Indonesia: Pendekatan ekologi gizi. Jurnal Gizi dan Pangan, 6(1), 59-65. https://doi.org/10.25182/jgp.2011.6.1.59-65 